\title{
FIBROSITIS AND NON-ARTICULAR RHEUMATISM
}

\author{
(International Congress Lecture)
}

\author{
By WALLACE GRAHAM, M.D., M.R.C.P., F.R.C.P. (C) \\ Assistant Professor of Medicine, University of Toronto; President, Canadian Rheumatism Association.
}

\begin{abstract}
ATUDY of the rheumatic diseases reveals that the A diseases of joints or the many forms of arthritis are well defined and therefore readily classified into their various groups. The diagnostic boundaries of theumatoid arthritis, osteoarthritis, Marie-Strumpell arthritis, gouty arthritis, \&c., are now more or less clear and universally accepted throughout the world. Although much remains to be learned about these articular diseases at least we all speak the same language, - and the results of treatment in one country may be compared with those in another.. Diagnostic agreement, based on the composite experience of scientific workers throughout the world, has, therefore, led to good treatment.
\end{abstract}

However, when we venture into the field of nonarticular rheumatism, particularly fibrositis, we find that all is confusion. Although fibrositis is considered by many the most common form of acute and chronic rheumatism there is little agreement concerning its definition, aetiology, pathology or treatment. The diagnostic boundaries defined in the various countries are so elastic that total experience cannot be assessed; as a result, advances in knowledge and treatment have been retarded.

This paper will deal primarily with the non-articular condition known as fibrositis, and, its purpose is to try to dispel some of the existing confusion and suggest a more positive approach to treatment.

The term 'fibrositis' was first introduced by Sir William Gowers in 1904 when he used it to denote the inflammatory changes in fibrous tissue which he felt were responsible for lumbago. Stockman (1920) first observed what he believed to be the underlying pathology, and he defined fibrositis as "a condition of chronic inflammation of the white fibrous tissue of the fascial aponeurosis, sheaths of muscle and nerves, ligaments, tendons, periosteum and subcutaneous tissues; occurring in all parts of the body and giving rise to pain, aching and stiffness and other symptoms, the result of preceding general infections or local infiammation or injuries."

This plausible theory was at first eagerly grasped by frustrated physicians seeking a cause for the manifold aches and pains in soft tissue structures, but subsequent histological studies failed to confirm the presence of chronic inflammation in the muscles involved.

For years the term fibrositis was received with reluctance and scepticism in America because of its defined pathology, and the name was not formally introduced until about 1936. - However, with increasing recognition of the distinctive clinical pattern fibrositis is now considered by most rheumatologists to be the most common form of acute and chronic rheumatism as well as the most controversial condition in the rheumatic field. Surely a condition with such widespread frequency is deserving of more serious attention than it has received.

A review of the literature on fibrositis unfortunately only leads to confusion. It reveals a number of authors vehemently defending a variety of theories regarding its cause but, in most cases, basic histological studies necessary for support of their theses are conspicuous by their absence.
Nevertheless, the term fibrositis which suggests an inflammatory cause, has crept into general use. No common cause has yet been determined and it is not established that inflammation of fibrous tissues is concerned, in its pathogenesis. Lacking a firm pathological background fibrositis has become the 'phantom disease,' the term being a veritable depot for many varieties of non-articular rheumatism, a situation which is confusing to students, physicians and physiotherapists, and which does not help to clarify the nature and identity of this very commorf complaint.

\section{Clinical Manifestations}

The chief symptoms are pain, stiffness and soreness, and the usual signs are tenderness and perhaps some limitation of movement. The most frequent sites are in the neck, shoulder, lower back and chest areas. The onset may be sudden or slow and insidious, and the course may be acute, subacute or chronic with remissions and exacerbations, the patient being relatively free of symptoms for varying periods. There is little or no effect upon the general health except that most patients complain of unusual degree of tiredness and easy fatigue which is not relieved by the night's rest. The distress is most often a dull ache, sometimes a buring sensation. Unlike arthritis the patient is worse after rest, worse in the morning and worse after sitting. The muscles seem to gel with rest, but the discomfort is relieved by activity. The patient can, to some extent, 'work it off' by exercise, but with the onset of fatigue the discomfort tends to return. The symptoms may be precipitated or augmented by cold, dampness, draughts and emotional upsets. Relief is often obtained, at least temporarily, by heat, such as a hot bath, salicylates, alcohol, and mental and physical relaxation. No constitutional disturbance is found and, apart from local tenderness, physical examination is notoriously negative. Palpations may disclose a localized tender area or myalgic spot, the so-called "trigger point' of fibrositis, and it would seem that thes?" tender areas may be largely responsible for the symptoms. Pressure on these areas may reproduce the patient's pain not only locally but in the areas of their referred pain. Injections of the area with a local anaesthetic may give complete relief, a full range of painless movement being restored. Pain may also be produced by increasing tension in the suspected structures by stretching movements.

Any discussion of the so-called fibrositis nodule is still entirely speculative. Many claim to have-felt them, but I know of no one who has actually seen one. For this reason it is probable that nodules have been over-stressed as a diagnostic aid and, as one author stated, they are 'only accessible to the finger of faith.' In 500 soldiers examined by Copeman and Pugh non-tender nodules were found with equal frequency in those with and those without the symptoms of fibrositis. Copeman's work has revealed that many such nodules represent herniations of fat which as a rule produce no symptoms.

It is probable that the fibrositis syndrome represents a yet unknown soft tissue reaction to a variety of different stimuli: traumatic, infectious, toxic, endocrine, psychogenic, 
\&c. It is not surprising that Babylonian confusion has arisen when a -multitude of conditions differing in their clinical picture and probably in cause, such as Dupuytren's contracture, bursitis, fat hernias and psychosomatic states. are included in the present classifications. Used in its broad sense, the term fibrositis has little more value than its predecessor rheumatism; it would seem important that an effort be made to establish a terminology based on cause which will make sense to the student, and which will lead to more fundamental treatment rather than "teeth, tonsils, aspirin and physiotherapy.'

\section{Classification}

Classified according to location fibrositis has been separated on an anatomic basis into several groups: (1) intramuscular '(myositis, muscular rheumatism), (2) periarticular, (3) tendinous, or fascial, (4) bursal, (5) perineural, and (6) panniculitis.

On clinical grounds fibrositis has been classified as: (1) primary-without demonstrable cause or sign of systemic disease; (2) secondary-a manifestation of diseases such as infections, associated with various forms of arthritis, such as rheumatoid, rheumatic fever, gout, \&c.; the result of strain or trauma, exposure, occupation, postural and structural abnormalities, \&c.

However, recent studies would suggest that if the patient is adequately studied, not only physically but psychologically, a cause for the symptoms will not be lacking, and the use of the term primary or idiopathic. fibrositis will seldom be necessary.

\section{Incidence}

The difficulty in establishing the incidence of fibrositis in relation to other rheumatic diseases is well shown in the figures published by various authors during World War II. The incidence of fibrositis in the British Forces was many times that seen in American troops subject to the same conditions. It is fair to assume that the symptoms suffered by both groups and studied by recognized observers were reasonably identical but, as Hench has pointed out, the discrepancy is due to the fact that no cases of psychogenic rheumatism were listed separately in the British series (and hence were included in the fibrositis group), whereas in the American group psychoneurosis was responsible for joint and muscle symptoms in one out of every five patients who complained of musculo-skeletal disorders, and these cases were not included in the fibrositis category. The conflicting figures published by leading rheumatologists support the view that the composite term fibrositis is too broad a label and should be discarded or at least broken down into many components if diagnostic unanimity is to be obtained.

\section{Aetiology}

The cause of fibrositis continues to be a controversial subject. Most investigators agree that the syndrome may be initiated by many factors, and the relation of injury, infection, exposure, fatigue, vascular, metabolic, postural, occupational and psychogenic conditions have all been put forward.

The direct infective theory, originally proposed by Stockman in 1920, now has little support. No organism has been demonstrated, and antibiotic drugs have not been of value in treatment. Nevertheless, the fibrositis syndrome does occur in association with influenza, malaria and other general infections. The relation of septic foci in teeth, tonsils, \&c., once strongly supported, is now, fortunately, losing ground rapidly. The theory that many rheumatic ailments owe their origin to infection in the oral cavity was originally proposed by William Hunter in 1910 . Over the years this plausible theory was widely accepted by physicians and dentists, and thousands of rheumatic patients were doomed to a toothless existence, the result of a theory utterly lacking in scientific support. After reviewing the unfortunate results of the application of this theory over a period of forty years it is astonishing that the wholesale removal of teeth and tonsils still exists as a 'cure' for many forms of rheumatism, including fibrositis.

Injury is considered a common cause of fibrositis: the result of a single incident or of repeated strain over a long period: As a rule the discomfort is short in duration unless the strain is maintained by occupational factors. There would seem to be no doubt that exposure to cold, wet, draughts, chilling and sudden changes in temperature can initiate an attack. Copeman feels that the symptoms may arise from the abnormal retention of fluid by fatty tissues, and that the origin of this selective swelling is probably endocrine in nature. Sir Thomas Lewis believed that the pain of fibrositis is of the same quality as that experienced by a patient with diminished circulation in the legs due to arterial disease, so-called intermittent claudication. Elliot is of the opinion that the myalgia arises from an irritated nerve root and that the tender spots are due to local muscle spasm: electromyographic studies were said to support this thesis. Steinberg, in the United States, favours a nutritional theory: that fibrositis is due to abnormal metabolism of vitamin $\mathrm{E}$. This theory has not been supported by others.

Halliday feels that most cases are psychogenic in origin. Many agree that emotional factors play an important role, and there would seem to be no doubt that the syndrome may be initiated or profoundly affected by the emotional state of the individual which reflects in the fibrous tissues with aching, pain and stiffness. Although this view has been challenged by those who defend the organic theories its validity has been .strongly supported by many authors.

It is probable that in most cases the fibrositis syndrome is precipitated by a psychosomatic disorder; this view is supported by the fact that the symptoms tend to come and go with a change in life situations and often disappear. when the emotional stress is over. Such a mechanism has long been accepted as a basis for cardiac and gastric complaints, but for some reason it has not been generally accepted in the field of rheumatism. This failure to include fibrositis among the psychosomatic states has been the chief obstruction to more effective treatment. In the study of non-articular rheumatism it is necessary to accept the basic concept that the fibrositis syndrome is a symptomcomplex of bodily distress and stiff action, and that people can become physically sore and stiff from mental as well as physical trouble. There is nothing radical about this attitude: it simply implies treating the person as well as the disease.

In our study of patients with so-called fibrositis it soon became evident that, as a group, they presented a fairly well defined emotional pattern. They were not psychoneurotics in the true sense of the term, but they were emotionally unstable and reacted with excessive responses both mental and physically. When they meet what most people would consider ordinary trials of life they. become tense, keyed up, tied in knots, and unable to relax. Their attitude was one of physical and mental restraint in which they felt emotions of anger, fear or resentment, but for various reasons they were unable to give vent to these feelings. A correlation' of the physical and mental phenomena suggested that in periods of prolonged emotional restraint these people have their fibrositic symptoms. If they can relax, as on a holiday, or with reassurance and relief of stress they become comfortable. As Halliday states, the symptoms are an outward manifestation of inner emotional tensions that have been provoked by disturbing external events or internal conflicts. Symptoms of being sore and stiff represent the patient's deep-seated feeling of being hurt by circumstances. In this way his inward feelings are, so to speak, pushed out of his mind and his attention is distracted from his inner problems and becomes focused on his bodily discomforts. Treatment, therefore, must be directed along the line of psychotherapy, 
as physiotherapy and other forms of treatment will only tend to fix the disability in the patient's mind. In such patients the resulting clinical picture may exactly duplicate the fibrositis syndrome with aching muscles, soreness and stiffness, local tenderness and trigger points.

It is very important, however, that the pain and discomfort must not be thought of as something imaginary in the patient's mind. Although some psychological fault is uniformly present in such patients the local stiffness, pain and tenderness is real and is due to a related physical fault, the exact nature of which is still iunknown. The emotional stress appears to cause a tautness in the muscles with a local neuromuscular or vascular disturbance which seems to come and go with the rise and fall of emotional tension. In some way this tautness must stimulate the muscle pain mechanism with resulting aching and tenderness, trigger points and referred sensations. . The electromyographic studies of Holmes and Wolff are of interest in this regard: Using needle electrodes in various areas they measured increased muscle tension and activity while the subject's feelings of hostility and resentment .were brought to peak intensity and then they noted that the muscle activity subsided rapidly with emotional support and reassurance. In 65 subjects with backache a sustained increase in motor and electrical activity was a common reaction when the subject was confronted by situations which threatened their security and engendered apprehension, conflict, anxiety, resentment, hostility, humiliation,' frustration and guilt. The reaction often provoked pain in the neck, back and extremities.

One cannot deprecate too severely the frequent use of the label 'arthritis' for these people who complain of muscular stiffness and aching. Accurate diagnosis is largely a matter of time and interest, and a few minutes spent inquiring about the person.and not the complaint will open new and - important avenues for treatment. As Sir William Osler said, "inquire not only as to what kind of sickness has this man, but also what kind of man has this sickness." As has been mentioned before, failure to explore the person and his environment can only lead to misfortunes in treatment. In dealing with these problems, Weiss castigates the organically minded physician who becomes a pathogenic agent in perpetuating the illness by his well meaning but mistaken and never-ending efforts to find a physical cause. "We must interest ourselves in not so much a lack of vitamins as the lack of emotional satisfaction in their lives ... instead of looking for focal infection we must look for focal conflict ... . what they need is-not a lumbar support byt psychological support.

The exact role of psychogenic factors in the aetiology of fibrositis remains a controversial subject, but to most observers this syndrome is seen in nervous and anxious people who seem to have a tension state and who find it difficult and impossible to relax.

In view of the many causative factors which have been outlined-infection, trauma, exposure, \&c.-it is obvious that fibrositis is not a disease entity but a syndrome brought about by a variety of widely separate conditions and, if considered in this light, much confusion will be avoided, as Dr. Himsworth said in a recent lepcture. It must be $^{-}$realized that a group of symptoms may be brought about by a chain of events and interference with the chain at any point may produce the same impairment of bodily function. The same group of symptoms, therefore, may arise from different causes. This thesis would appear to provide a satisfying explanation for the controversial origin of fibrositis.

\section{Pathology}

Pathological studies have not yet revealed the fundamental nature of the syndrome. Fibrositic nodules and thickenings, varying in size, shape and location, have been described by many authors but, in spite of biopsy studies, there is as yet no typical microscopic appearance whereby they can be indentified histologically. Authors have pictured the out-pourings of serofibrinous exudate, the proliferation of fibroblasts and laying down of fresh fibrous tissue as the pathological basis for the symptomatology, but such theories still lack microscopic support. A pathological basis for pain and local tenderness in a few cases has been adequately established in the herniated fat nodule, and many nodules, tender or non-tender, formerly referred to as fibrositic nodules undoubtedly represent such fat herniation. Similarly, laboratory studies have failed to clarify the situation.

\section{Treatment}

The beneficial but temporary effect of rest, heat, massage, analgesics, the injection of local anaesthetics and an exercise programme are accepted, but fundamental treatment of the syndrome must naturally be directed against the agent which is felt to be the cause. The tendency to group many forms of non-articular rheumatism under one label has led to an unfortunate 'fibrositis treatment' which has been useless in the majority of cases. The hypothesis that fibrositis is a chronic inflammatory lesion of fibrof muscular tissues has led to the extensive misuse of massage in an attempt to relieve the inflammation and cure the patient's symptoms. The fact that no such inflammatory lesion exists explains why thousands of physiotherapists all over the world have wasted millions of hours rubbing patients, with little success in 'curing' them or even significantly relieving their symptoms. Relief for short periods may follow massage, but surely the attack should be on the cause and not on the effect.,

Most patients who have fibrositis think that they have arthritis and are filled with the fear and anxiety which accompanies this diagnosis. Reassurance that the trouble does not represent progressive destructive joint disease lifts a great weight from the patient's mind and is the most potent factor in treatment.

When a psychological fault has definitely been established as the cause, psychotherapy and not physiotherapy in its ordinary sense is indicated. As Weiss suggests: "When we say to these people that their aches and pains and fatigue are due to the fact that they are always in a state of tension; that they do not know how to relax, even at night, and that because they are taut their muscles are crying out in protest with aches and pains, it carries conviction and provides a stepping-stone for them to begin to talk about their emotional problems." Such patients can often be shown from their own history that their symptoms increase when they are emotionally upset and subside af they gain mental physical relaxation. In the tension group an effort should be made to teach the patient how to relax, which requires only a limited amount of time and patience on the part of the physiotherapist but, what is more important, it stimulates the patient to make his own contribution towards the control of his disability.

The physician or the physiotherapist cannot change the personality of the patient and seldom can they alter the environment, but at least an effort can be made to determine and treat the cause rather than thrust all patients with nonarticular symptoms into the grab-bag labelled fibrositis. In the tension group an explanation of the mechanism of their pain will often lead to a complete change in attitude and consequent relief.

While waiting for further study to clarify the many components of non articular rheumatism it would seem beneficial to consider fibrositis not as a clinical entity but as a syndrome with a wide variety of causes. The patient will then more likely receive the physical and psychological investigation which his problem demands, and this should lead to a more positive approach to treatment. 